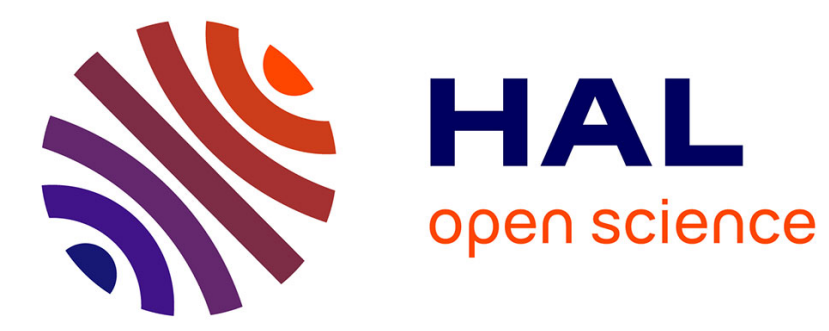

\title{
$\gamma$-Aminobutyric acid and related amino acids in plant immune responses: Emerging mechanisms of action
}

Łukasz Pawel Tarkowski, Santiago Signorelli, Monica Höfte

\section{To cite this version:}

Łukasz Pawel Tarkowski, Santiago Signorelli, Monica Höfte. $\gamma$-Aminobutyric acid and related amino acids in plant immune responses: Emerging mechanisms of action. Plant, Cell and Environment, 2020, 14 p. $10.1111 /$ pce. 13734 . hal- 02548485

\section{HAL Id: hal-02548485 \\ https://hal.inrae.fr/hal-02548485}

Submitted on 26 May 2020

HAL is a multi-disciplinary open access archive for the deposit and dissemination of scientific research documents, whether they are published or not. The documents may come from teaching and research institutions in France or abroad, or from public or private research centers.
L'archive ouverte pluridisciplinaire HAL, est destinée au dépôt et à la diffusion de documents scientifiques de niveau recherche, publiés ou non, émanant des établissements d'enseignement et de recherche français ou étrangers, des laboratoires publics ou privés.

\section{(ㅇ)(1) $\$$}

Distributed under a Creative Commons Attribution - NonCommercial - NoDerivatives $\mid 4.0$ 
Title: GABA and related amino acids in plant immune responses: emerging mechanisms of action

Authors: Łukasz Paweł Tarkowski ${ }^{1}$, Santiago Signorelli ${ }^{2,3,4}$, Monica Höfte ${ }^{5}$

${ }^{1}$ Seed Metabolism and Stress team, INRAE Angers, UMR1345 Institut de Recherche en Horticulture et Semences, Bâtiment A, 42 rue Georges Morel, CS 60057, 49071 Beaucouzé cedex, France.

2Laboratorio de Bioquímica, Departamento de Biología Vegetal, Facultad de Agronomía, Universidad de la República, Av. Garzón 780, Sayago CP 12900, Montevideo, Uruguay.

${ }^{3}$ The School of Molecular Sciences, Faculty of Science, The University of Western Australia, 35 Stirling Highway, Crawley CP 6009, WA, Australia.

${ }^{4}$ Australian Research Council Centre of Excellence in Plant Energy Biology, University of Western Australia, 35 Stirling Highway, Crawley CP 6009, WA, Australia.

${ }^{5}$ Laboratory of Phytopathology, Department of Plants and Crops, Faculty of Bioscience Engineering, Ghent University, Coupure Links 653, B-9000 Gent, Belgium.

\section{Contact Information:}

${ }^{1}$ lukasz.tarkowski@inrae.fr

\section{Funding:}

Ł.P.T. is funded by the National Institute of Research for the Agriculture, the Alimentation and the Environment (INRAE, France). S.S. is an associate member of the National System of Researchers (SNI, Uruguay).

\section{Abstract:}

This article has been accepted for publication and undergone full peer review but has not been through the copyediting, typesetting, pagination and proofreading process which may lead to differences between this version and the Version of Record. Please cite this article as doi: $10.1111 /$ pce. 13734 
The entanglement between primary metabolism regulation and stress responses is a puzzling and fascinating theme in plant sciences. Among the major metabolites found in plants, $\gamma$-aminobutyric acid (GABA) fulfils important roles in connecting $C$ and $N$ metabolic fluxes through the GABA shunt. Activation of GABA metabolism is known since long to occur in plant tissues following biotic stresses, where GABA appears to have substantially different modes of action towards different categories of pathogens and pests. While it can harm insects thanks to its inhibitory effect on the neuronal transmission, its capacity to modulate the hypersensitive response (HR) in attacked host cells was proven to be crucial for host defenses in several pathosystems. In this review, we discuss how plants can employ GABA's versatility to effectively deal with all the major biotic stressors, and how GABA can shape plant immune responses against pathogens by modulating reactive oxygen species balance in invaded plant tissues. Finally, we discuss the connections between GABA and other stress-related amino acids such as BABA ( $\beta$-aminobutyric acid), glutamate and proline.

\section{Keywords:}

GABA, BABA, biotic stress, glutamate, proline, hypersensitive response, primary metabolism, ROS.

\section{Acknowledgments}

\section{Summary statement}

Recent research on GABA in plants highlighted a variety of functions concerning biotic stress responses including its interference with quorum sensing, the enhancement of plant endurance and toxicity to herbivorous. Connections of GABA metabolism with other stress-related amino acids provide further indirect modes of action during the setup of immune responses.

\section{Cover Image Submissions}




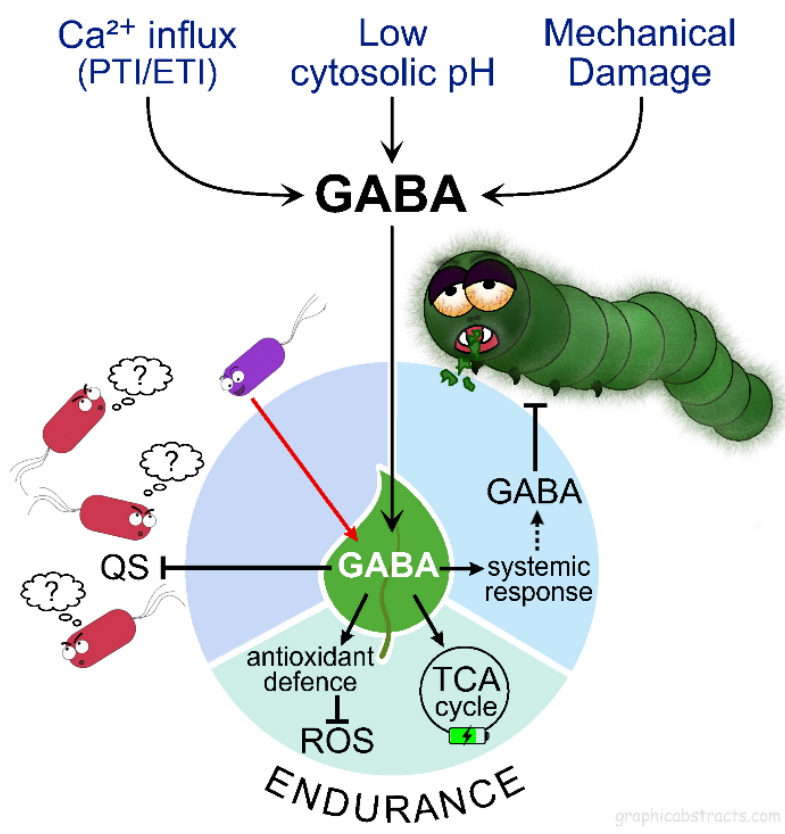

\section{Authorship}

Ł.P.T. conceived the manuscript and wrote the first draft, S.S. contributed to drafting the manuscript and prepare figures, M.H. contributed to drafting the manuscript. All authors gave their final approval of the manuscript to be published.

\section{Acknowledgments}

\section{Conflict of Interest Statements}

The authors declare the absence of any conflict of interest. 


\section{i. Title}

GABA and related amino acids in plant immune responses: emerging mechanisms of action

\section{ii. Abstract}

The entanglement between primary metabolism regulation and stress responses is a puzzling and fascinating theme in plant sciences. Among the major metabolites found in plants, $\gamma$-amino butyric acid (GABA) fulfils important roles in connecting $\mathrm{C}$ and $\mathrm{N}$ metabolic fluxes through the GABA shunt. Activation of GABA metabolism is known since long to occur in plant tissues following biotic stresses, where GABA appears to have substantially different modes of action towards different categories of pathogens and pests. While it can harm insects thanks to its inhibitory effect on the neuronal transmission, its capacity to modulate the hypersensitive response (HR) in attacked host cells was proven to be crucial for host defenses in several pathosystems. In this review, we discuss how plants can employ GABA's versatility to effectively deal with all the major biotic stressors, and how GABA can shape plant immune responses against pathogens by modulating reactive oxygen species balance in invaded plant tissues. Finally, we discuss the connections between GABA and other stress-related amino acids such as BABA, glutamate and proline.

\section{iii. Keywords}

GABA, BABA, biotic stress, glutamate, proline, hypersensitive response, ROS.

\section{iv. Main text:}

\section{Introduction}

Plants can modify various physiological and molecular parameters in response to biotic stressors to find the most suitable defense strategy against specific invaders (Miller et al., 2017). The perception of Invasion Patterns (IP), originated directly or indirectly from a pest or a pathogen, leads to the activation of immune responses mediated by phytohormones and their intricated network of signaling cascades (Bigeard et al., 2015; Cook et al., 2015; Pieterse et al., 2012). Besides signaling pathways, compelling evidence indicates that re-shaping primary metabolism is a widespread strategy used by plants to better resist biotic stressors (Bezrutczyk et al., 2018; Rojas et al., 2014). Based on pathogen lifestyle, adjustments of metabolic fluxes of soluble sugars and amino acids can be decisive to sustain 
strategies aimed to fuel host defenses or to make the environment more hostile to the pathogen (Seifi et al., 2013a). On the other hand, several pathogens have developed molecular tools to hijack critical hubs of host primary metabolism, such as enzymes and transporters, to take advantage of host resources (Engelsdorf et al., 2013; Wittek et al., 2017). To date, important roles in plant defense were established for several primary metabolites, such as sucrose (Suc) and glutamate (Glu) (Seifi et al., 2013a; Tauzin and Giardina, 2014). Among such metabolites, $y$-aminobutyric acid (GABA) stands out for the vast body of literature linking it to positive roles in plant stress physiology (Bown and Shelp, 2016; Mahmoud et al., 2017; Wang et al., 2019).

GABA is a non-proteinogenic amino acid that is mostly known for its function as an inhibitory neurotransmitter in vertebrates (Wu \& Sun, 2015). It can be found in Bacteria, Archaea and Eukaryota kingdoms, where it seems to fulfill an incredible variety of roles (Bown \& Shelp, 2016; Feehily \& Karatzas, 2012; Gou et al., 2012; Kim et al., 2014). In plants, endogenous accumulation of GABA is known to occur in response to many stresses, such as heavy metal accumulation, salinity, heat shock and wounding (Kinnersley \& Turano, 2000; Seifikalhor et al., 2019). Furthermore, GABA is a central node in balancing metabolic fluxes between carbon (C) and nitrogen $(\mathrm{N})$ metabolism (Fait et al., 2008; Michaeli \& Fromm, 2015). Signaling roles of GABA were described in animals since the fifties (Elliott and Jasper, 1959), where GABA binds to two classes of neuronal receptors, named GABA $A$ and $G A B A_{B}$. $\mathrm{GABA}_{A}$ is an ionotropic receptor that works as $\mathrm{Cl}^{-}$channel, while $\mathrm{GABA}_{B}$ is coupled with a $\mathrm{G}$-protein (Chebib \& Johnston, 1999). A receptor for GABA in plants was identified only in 2015 in an aluminumactivated malate transporter (ALMT) protein (Ramesh et al., 2015), although evidence for signaling roles for GABA in plants had been already described before (Baum et al., 1996; Barbosa et al., 2010; Lancien and Roberts, 2006). A multitude of biological processes seem to be linked to GABA signaling, such as regulation of 14-3-3 genes and control of developmental processes such as germination and pollen tube growth (Lancien \& Roberts, 2006; Palanivelu et al., 2003; Sheng et al., 2018). This body of evidence delineates GABA as an important molecule in connecting primary metabolism to signaling in plant cells (Bown \& Shelp, 2016; Seifikalhor et al., 2019). GABA-dependent modulation of neuronal transmission, or GABAergic signaling, is known to profoundly impact the vertebrate immune system (Barragan et al., 2015). The majority of studies about GABA in plants focus on abiotic stress, but reports about the involvement of GABA metabolism and signaling in plant immunity are steadily increasing, concerning both pests and pathogens (Scholz et al., 2015; Tarkowski et al., 2019; Yang et 
al., 2017). These recent advances are starting to shed light on the underlying mechanisms associated with GABA-induced resistance. Here, we review these emerging mechanisms with a focus on GABA accumulation processes, its mechanisms of action in relation to different types of biotic interactions and its interplay with reactive oxygen species (ROS). We also highlight the roles in plant immunity of amino acids closely related to GABA and we propose a novel perspective about the role of GABA, Glu and proline (Pro) in coordinating metabolic resources and ROS homeostasis during biotic challenges.

\section{Mechanisms triggering GABA accumulation during biotic stress}

\subsection{Glu-dependent GABA shunt activation is induced in response to fungal and bacterial pathogens}

Microbe recognition usually results in pattern-triggered immunity (PTI) as the first mechanism of defense, and effector-triggered immunity (ETI) as a second but more potent layer of defense (Jones \& Dangl, 2006). The activation of both immune layers is characterized by an increased $\mathrm{Ca}^{2+}$ influx (Seybold 2014), which is among the earliest responses that occur following pathogen recognition, and as such is considered to be immediately downstream of ligand-receptor recognition events (Seybold et al., 2014). Second messengers originated from the intracellular domains of receptors or co-receptor proteins such as CGMP are retained to mediate the activation of $\mathrm{Ca}^{2+}$ channels, such as the ones belonging to the CNGC (Cyclic Nucleotide Gated Channels) family (Ma et al., 2012; Zhao et al., 2013). The $\mathrm{Ca}^{2+}$ liberated in the cytosol binds to several $\mathrm{Ca}^{+2}$ binding domains present on proteins such as calmodulin ( $\mathrm{CaM}$ ), calcineurin B-like (CBLs) proteins, and $\mathrm{Ca}^{+2}$-dependent protein kinases (CDPKs) (Schulz et al., 2013; Steinhorst \& Kudla, 2013). These events lead to downstream activation of several transcription factors that modulate important immune responses, such as biosynthesis of the hormone salicylic acid (SA) and programmed cell death (PCD) induction (De la Torre et al., 2013; Zhang et al., 2010).

The primary pathway to synthesize GABA in plants is known as the GABA shunt (Fait et al., 2008) (Figure 2). In this pathway, glutamate (Glu) is decarboxylated to GABA by the action of glutamate decarboxylase (GAD) in the cytosol (Forde \& Lea, 2007) (Figure 2). Interestingly, most plant GADs have a calmodulin-binding domain which triggers their decarboxylating activity following increases of cytosolic $\mathrm{Ca}^{2+}$ levels at neutral pH (Shelp et al., 2006; Snedden et al., 1995). In this way, pathogeninduced GABA accumulation can be controlled by $\mathrm{Ca}^{2+}$ influx produced as a consequence of the immune response of plants. Moreover, GAD is known to be activated following cytosol acidification 
(Shelp et al., 2006; Snedden et al., 1995). In fact, recognition of pathogens such as bacteria and fungi was proven to trigger GABA accumulation in several plant species, such as bean (Phaseolus vulgaris L.), tomato (Solanum lycopersicon L.) and soybean (Glycine max L.) (Copley et al., 2017; O'Leary et al., 2016; Wang et al., 2019) (Table 1). The accumulated GABA is presumed to be transported to the mitochondria, where it undergoes deamination via GABA transaminase (GABAT) to succinic semialdehyde (SSA) (Shelp \& Zarei, 2017). This can be further oxidized to succinate by succinic semialdehyde dehydrogenase (SSADH) to directly fuel the TCA cycle (Fait et al., 2008; Michaeli et al., 2011), thus linking amino acid to carbohydrate and organic acid metabolism. Alternatively, SSA can be reduced to $\gamma$-hydroxybutyrate (GHB) via $p$-hydroxybutyrate dehydrogenase (GHBDH) (Breitkreuz et al., 2003). This usually takes place under anaerobic conditions where SSADH activity is inhibited.

Research on tomato sitiens mutants (unable to accumulate $A B A$ ), unable to accumulate the phytohormone abscisic acid (ABA), showed that increased activity of the GABA shunt contributes to resistance towards the necrotrophic fungus Botrytis cinerea (Seifi et al., 2013b). Accordingly, accumulation of GABA in Arabidopsis (Arabidopsis thaliana L.) leaves challenged with the bacterium Pseudomonas syringae DC 3000 was associated with induction of GAD gene, whereas increased GABAT activity was documented in rice leaves following infection with the rice blast fungus Pyricularia oryzae (syn. Magnaporthe oryzae) (Ward et al., 2010; Wu et al., 2006). Results in tomato sitiens mutants suggest that overactivation of the GS/GOGAT cycle is the main source of cytosolic Glu used to supply the GABA shunt (Seifi et al., 2013b). However, the GS/GOGAT cycle can also be a deleterious electron sink under decreased photosynthetic activity, an event that typically occurs in many plantpathogen interactions (Liu et al., 2010). Regulation of the GS/GOGAT cycle is key to control the C/N ratio and it is typically associated with metabolic cues, such as changes in $\mathrm{N}$ availability, or changes in carbohydrates and amino acids levels (Ishiyama et al., 2004; Oliveira \& Coruzzi, 1999). Besides local regulation of enzymatic activities, Glu import from distal areas from the infection site was suggested to occur during $B$. cinerea infection in sunflower (Helianthus annuus L.) to supply substrates for the synthesis of defense-related compounds (Dulermo et al., 2009).

\subsection{Glu-independent GABA accumulation under pathogen attack}

Glu decarboxylation is not the only way to synthesize GABA in plants, as GABA can be obtained via polyamine (PA) degradation as well, which is performed by amine oxidases (AOs) enzymes, divided in 
polyamine oxidases (PAO) and diamine oxidases (DAO) (Flores \& Filner, 1985; Shelp et al., 2012). PA are organic compounds containing two or more amino groups suggested to cover several functions in plant physiology (Aloisi et al., 2016; Bitrián et al., 2012; Galston \& Sawhney, 1990). Consistent with the role of GABA in plants, PA metabolism is documented to be modulated in response to various stresses (Liu et al., 2015; Seifi \& Shelp, 2019). Rice cell suspensions exposed to treatments with $P$. oryzae lysates showed increased GABA levels in a GAD-independent manner (Forlani et al., 2014), and grape (Vitis vinifera L.) varieties with high catabolism of PA were shown to possess higher GABA levels and increased resistance towards B. cinerea (Hatmi et al., 2015). Likewise, the tolerance of maize (Zea mays L.) towards Aspergillus flavus infection was correlated to higher catabolism of PAs when comparing resistant and susceptible maize lines in in vitro experiments (Majumdar et al., 2019). PAdependent GABA synthesis seems to be relevant also in the context of bacterial infections. CaADC1, an arginine decarboxylase from pepper (Capsicum annuum L.), is able to bind AvrBsT, an effector from the bacterial pathogen Xanthomonas campestris, and induce a hypersensitive response (HR) to limit pathogen spread (Kim et al., 2013). HR is a form of plant defense based on PCD which is typically due to the accumulation of ROS at the infection site (Heat, 2000). Arginine generated by CaADC1 can be directed to PA biosynthesis, and CaADC1 mutants displayed decreased GABA levels and increased susceptibility towards $X$. campestris (Kim et al., 2013). Furthermore, a pathway from Pro, involving non-enzymatic and enzymatic reactions, was suggested for the synthesis of GABA under oxidative stress conditions (Signorelli et al., 2015). However, the occurrence of such events during plantpathogen interactions has never been observed so far. Finally, it is important to remark that the subcellular localization of GABA accumulation can be critical in determining the outcomes of the plantpathogen interaction. While intracellular GABA accumulation can efficiently fuel metabolic pathways related to plant defense, extracellular accumulation may be beneficial for pathogens that reside in the apoplast and can compete for GABA assimilation, such as Pseudomonas syringae or Cladosporium fulvum (O'Leary et al., 2016; Rico \& Preston, 2008; Solomon \& Oliver, 2002). Moreover, pathogens like P. syringae were demonstrated to be nutritionally adapted to plants that accumulate high apoplastic GABA levels such as tomato (Rico \& Preston, 2008).

\subsection{The puzzling mechanism of insect-triggered GABA accumulation}

Accumulation of GABA following wounding was documented a long time ago (Wallace et al., 1984), and further studies demonstrated that this event can be induced by mechanical stimulation caused by 
insect footsteps and feeding (Bown et al., 2002; Scholz et al., 2015). However, further investigations suggested that GABA accumulation is neither dependent on cytosolic $\mathrm{Ca}^{2+}$ increase induced by wounding or insect feeding nor on the direct transport of GABA from wounded to systemic leaves. The authors concluded that electrophysiological events might represent reasonable signaling candidates to trigger GABA accumulation (Scholz et al., 2017), a hypothesis in line with the postulated role of GABA in regulating membrane excitability in plants via its binding to ALMT anionic channels (Žárský, 2015). Our knowledge about the mechanism triggering GABA accumulation during insect attack requires further research.

\section{A molecular Swiss knife: GABA functions in relation to pathogen lifestyle}

\subsection{GABA effects on herbivores and nematodes: a question of nerves}

The first finding of the involvement of GABA in biotic stress responses came from studies on soybean plants infested by leaf-roller (Choristoneura rosaceana) larvae (Ramputh \& Shelp, 1996), although its involvement in responses to insects was postulated before based on observations on woundinginduced GABA accumulation (Wallace et al., 1984). The authors noted that the development and survival of larvae were compromised when GABA was added to their diet and that GABA accumulates within minutes in leaf tissue after mechanical stimulation (Ramputh \& Shelp, 1996). Further studies demonstrated that rapid accumulation of GABA is triggered by the crawling of the tobacco budworm in tobacco (Nicotiana tabacum L.) leaves, and that those budworm larvae have a strong feeding preference towards wild-type (WT) plants compared to mutants accumulating higher GABA levels (Bown et al., 2002; MacGregor et al., 2003). The authors of these works hypothesized a connection between the role of GABA as a neurotransmitter and defense against insects. The inhibitory action of GABA on neuromuscular junctions provokes paralysis in insects (Irving et al., 1979), and several classes of pesticides target GABA-responsive $\mathrm{Cl}^{-}$channels by acting as GABA agonists or antagonists to disrupt neuromuscular activity (Casida \& Durkin, 2015). Thus, insect-induced GABA accumulation is likely to be a defensive strategy used to specifically target phytophagous species that developed a neuronal system (Figure 1). Consistently, experiments performed on GAD overexpressing (OX) tobacco plants (able to accumulate higher GABA levels) infested with the northern root-knot nematode showed that WT plants possessed a significantly higher amount of nematode egg masses on their root surface than 
GAD OX lines (Mclean et al., 2003), suggesting a similar function of plant-derived GABA against insects and nematodes (Shelp et al., 2006).

\subsection{GABA accumulation can be a double-edge sword in relation to (hemi)biotrophs}

Alteration of GABA metabolism in plants as response to (hemi)biotrophic pathogens is widely documented, however, some (hemi)biotrophic pathogens can use GABA as nutrient source as well, thus taking advantage of increased GABA levels in the apoplastic environment (Rico \& Preston, 2008; Solomon \& Oliver, 2002). GABA was shown to be the main $\mathrm{N}$ source for Cladosporium fulvum during its infection in tomato, where it is the most abundant amino acid in the apoplast (Rico \& Preston, 2008; Solomon \& Oliver, 2002). Accordingly, P. syringae pv. tomato DC3000 strains mutated for all the three GABAT isoforms displayed impaired growth, but the same authors also demonstrated that decreased GABA levels in Arabidopsis GABAT mutants compromise HR elicitation (Park et al., 2010). Increased GABA levels suppress the expression of the type III secretion system (T3SS) of $P$. syringae pv. tomato DC3000, thus decreasing virulence and capacity to elicit an immune response (Park et al., 2010). Consistently, data from the pepper-X. campestris pathosystem suggested that GABA is required for a correct elicitation of $\mathrm{HR}$, and studies on bean infected with avirulent $P$. syringae demonstrated that GABA accumulation is correlated with the onset of ETI (O'Leary et al., 2016). It should be noted that GABA is not a preferred nutrient for $P$. syringae pv. tomato DC3000 since uptake of apoplastic GABA via the GabP permease is only activated when favorite $\mathrm{C}$ and $\mathrm{N}$ sources such as aspartate and glutamate are depleted (McCraw et al., 2016). Likewise, the bean pathogen P. syringae pv. phaseolicola only starts to consume GABA when preferred metabolites are depleted (O'Leary et al., 2016). These data suggest that pathogenic Pseudomonas bacteria may use apoplastic GABA as a signal indicating nutrient depletion. McCraw et al. (2016) proposed that the repression of the T3SS and HR by GABA might be a pathogen strategy to save energy. On the other hand, high GABA levels might interfere with pathogenic growth as well. Metabolomic analysis of Lr34, a wheat (Triticum aestivum L.) variety highly resistant towards the biotrophic fungus Puccinia triticina, revealed an overactivation of several processes related to primary metabolism compared to a susceptible variety during infection, including the GABA shunt (Bolton et al., 2008). GAD Knock Out (KO) tomato plants exhibited increased susceptibility towards the hemibiotroph Ralstonia solanacearum, the causal agent of bacterial wilt (Wang et al., 2019), evidencing that GABA contributes to plant defense against $R$. solanacearum. 
However, following $R$. solanacearum inoculation, GABA biosynthesis via GAD, alongside the methionine cycle, is suppressed while GABA catabolism is rapidly stimulated (Wang et al., 2019). Such data might indicate that suppression of GABA accumulation is a pathogen strategy to weaken the host during the early infection phases.

Bacterial plant pathogens are mostly biotrophs or hemi-biotrophs (Kraepiel \& Barny, 2015; Tripathi, 2017), and the majority of them relies on quorum sensing (QS) to assess population density and consequently regulate critical physiological processes required for virulence, such as biofilm formation, secretion of toxins and siderophores and motility (Liu et al., 2008; von Bodman et al., 2003). Intriguingly, GABA derived from tobacco plants was found to negatively regulate $Q S$ in Agrobacterium tumefaciens, and GAD OX tobacco plants were found to be more resistant towards $A$. tumefaciens infection compared to WT (Chevrot et al., 2006) (Figure 1). Further research on this pathosystem demonstrated that GABA-mediated QS interference compromises the dissemination of the virulent $\mathrm{Ti}$ plasmid through horizontal transfer in Agrobacterium colonies (Lang et al., 2015). Mechanistic bases of GABA-dependent regulation of QS were established with the discovery of a GABA-binding protein from A. tumefaciens, Atu4243, structurally similar to polyamine binding proteins (Planamente et al., 2012). Binding between GABA and Atu4243 results in reduced aggressiveness towards the host and increased degradation of the QS signal (Planamente et al., 2012). In addition to this, it is known that GABA can be found in significant amounts in root exudates of wheat and tomato (Reyes-Darias et al., 2015; Warren, 2015). The non-pathogenic root colonizing bacterium Pseudomonas putida strain KT2440 was shown to have a specific GABA chemoreceptor. Deletion of the $m c p G$ gene encoding this receptor reduced root colonization, indicating that GABA acts as a signaling molecule that mediates interaction with (beneficial) root colonizing bacteria (Reyes-Darias et al., 2015). In the biocontrol strain Pseudomonas protegens CHAO high intracellular GABA levels promote planktonic growth and root colonization and diminish biofilm formation (Takeuchi, 2018). Such a variety of roles at the plantmicroorganisms interface points to the centrality of GABA in interkingdom signaling. In agreement with this notion, GABA was shown to be involved in coordinating metabolic balances in rhizobialegume symbiosis (Nasr Esfhani et al., 2016; Sulieman \& Schulze, 2010) and symbiosis with mutualistic microbes such as Piriformospora indica (Hua et al., 2017).

\subsection{GABA promotes cell viability under necrotrophic attack}


Research on the Arabidopsis- $B$. cinerea pathosystem evidenced that plants overexpressing the cytosolic aspartate transaminase 1 (AAT1) gene displayed increased susceptibility towards $B$. cinerea infections, which was suggested to be caused by the repression of Glu-consuming pathways important for plant defense, such as the GABA shunt (Brauc et al., 2011). Further investigations on tomato sitiens mutants revealed that metabolic supply to the TCA cycle through GABA shunt overactivation is critical for containing $B$. cinerea spread and maintaining the viability of cells surrounding the necrotic lesion (Seifi et al., 2013b). This research suggested that GABA plays the dual role of fueling the TCA cycle and providing $\mathrm{N}$ to the attacked cells for the synthesis of defense-related compounds, and by limiting $\mathrm{HR}$ spread to healthy cells through the formation of an HR-like ring surrounding the spreading lesion (Seifi et al., 2013b) (Figure 1). A kind of defensive mechanism targeted to support cell viability is referred to as 'endurance', in opposition to 'evasion' strategies oriented to facilitate cell death spreading from the attacked area (Seifi et al., 2013a). Endurance-based strategies are postulated to be effective against necrotrophs, however, they require great amounts of metabolic energy. Consistently, a strong depletion of Glu and GABA levels was recorded in soybean leaves infected with the necrotroph Rhizoctonia solani (Copley et al., 2017). Endurance strategies would likely need to be supplied with substrates coming from distal, healthy areas of the plant (Seifi et al., 2013a). In sunflower, transport of Glu to regions infected by $B$. cinerea was predicted to be a mechanism to supply $N$ in the infected area to contrast necrotroph-induced senescence (Dulermo et al., 2009). In agreement with this notion, it is known that exogenous GABA applications can be effective in reducing $B$. cinerea symptoms on both leaves and fruits of tomato (Seifi et al., 2013b; Sun et al., 2019). Exogenous application of GABA in Arabidopsis resulted in the increase of the activity of enzymes associated with $\mathrm{N}$ metabolism such as nitrate reductase (NR) and GOGAT (Barbosa et al., 2010), thus it remains possible that GABA can modulate metabolic adjustments in response to necrotrophs by functioning also as a signaling molecule rather than as a mere metabolite (McCraw et al., 2016), although such hypothesis awaits further investigation.

Interaction of GABA with defense-related phytohormones, such as $\mathrm{SA}$, jasmonic acid (JA) and ethylene (ET) (Pieterse et al., 2012), has been sporadically characterized so far (Scholz et al., 2015; Hijaz et al., 2018). Exogenous GABA application on sweet orange (Citrus $x$ sinensis Osbeck) plants triggered the accumulation of several phytohormones, included SA, JA and abscisic acid (ABA) (Hijaz et al., 2018). We recently suggested that GABA accumulation following $B$. cinerea infection in lettuce (Lactuca 
sativa L.) leaves primed with inulin (a fructan, fructose-based polysaccharide naturally occurring in plants) and oligogalacturonides (OGs, a pectin-derived elicitor) is dependent on ET signaling. We supported this hypothesis by using a pharmacological approach based on the use of the ET signaling inhibitor 1-methylcyclopropene (1-MCP) (Tarkowski et al., 2019). Wang et al. (2019) proposed that the accumulation of $S$-adenosyl-methionine, produced by the inhibition of the methionine cycle, is important to sustain the ET biosynthesis. Together, these findings may suggest that the methionine cycle is inhibited, causing ET accumulation which in turn enhances the positive effect of GABA on plant defense. Moreover, exogenous application of ET biosynthesis inhibitor AVG (aminoethoxyvinylglycine) was reported to impact negatively GABA accumulation in creeping bentgrass (Agrostis stolonifera $\mathrm{L}$.) subjected to heat stress (Jespersen et al., 2015). Intriguingly, reports from sunflower and longstalk starwort (Stellaria longipes Goldie) showed that GABA can stimulate ET synthesis in leaf tissue (Kathiresan et al., 1997; 1998). ET is also known to regulate $\mathrm{Ca}^{2+}$ influx, which affects GAD activity, in the cell during symbiotic interactions between rhizobia and barrel medic (Medicago truncatula L.) (Oldroyd et al., 2001). Taken together, these studies suggest that ET and GABA metabolism/signaling are intertwined in plant stress responses. In light of the fundamental role of ET in regulating plant resistance towards necrotrophs (Broekgaarden et al., 2015; Pieterse et al., 2012), a better understanding of its crosstalk with GABA will be an attractive target for future research.

\section{GABA impacts plant defense by modulating ROS homeostasis}

\subsection{Glu-derived GABA metabolism and signaling shape ROS homeostasis during biotic stress}

A relationship between GABA metabolism and regulation of oxidative stress was first proposed when research on Arabidopsis KO mutants for SSADH indicated that a functional GABA shunt is required to limit ROS intermediates during stress conditions such as heat and UV exposure (Bouche et al., 2003). This research suggested that GABA shunt supplies NADH and succinate under stressful conditions to maintain cellular oxidative balance, and allows to bypass steps of the TCA cycle involving enzymes sensitive to oxidative stress such as aconitase (Bouche et al., 2003; Fait et al., 2005). Further investigations in this direction suggested that $\mathrm{Ca}^{2+}$-dependent activation of the GABA shunt is critical for ROS scavenging under UV-light stress in Arabidopsis (Al-Quraan, 2015). Notably, exogenous application of GABA is known to reduce oxidative damage under abiotic stresses such as salinity, heat, hypoxia, cold and heavy metals toxicity (Li et al., 2016; Song et al., 2010; Wang et al., 2014; Wang et 
al., 2017). The reduced oxidative damage was associated with increased activity of antioxidant enzymes such as catalase (CAT), superoxide dismutase (SOD), and the ascorbate-glutathione cycle enzymes (Wang et al., 2014; Mahmud et al., 2017; Wang et al., 2017; Kalhor et al., 2018). Some of these authors proposed GABA-induced signaling to explain such reprogramming of the cellular antioxidant machinery (Vijayakumari \& Puthur, 2016; Wang et al., 2017). It is worth mentioning that the direct scavenging of ROS by GABA is not known and remains largely undocumented. However, exogenous GABA treatments showed to be effective in counteracting biotic stress in crops such as tomato and pear (Pyrus pyrifolia Nakai.), mainly through the induction of both transcript and protein activity levels of antioxidant enzymes, which ultimately restricted HR (Yang et al., 2017; Yu et al., 2014). Such conclusions agree with studies on rice and tomato sitiens mutants, where increased energetic supply to cells attacked by fungal pathogens through GABA shunt overactivation was postulated to be critical to contain HR spread (Seifi et al., 2013b; Wang et al., 2006). Nevertheless, these authors suggested that coordination between ROS production inside the lesion and increased energetic supply in the outer layer results in an effective HR event against pathogens that are typically able to take advantage of cell death, such as necrotrophs (Govrin \& Levine, 2000; Seifi et al., 2013b), remarking how the host can shape its defense response by co-regulating GABA and ROS dynamics in order to adapt to pathogen invasion strategies. Consistently, studies on the lettuce- $B$. cinerea pathosystem showed that increased resistance of inulin and OGs-primed leaves was accompanied by an increase in both $\mathrm{H}_{2} \mathrm{O}_{2}$ and GABA levels compared to controls (Tarkowski et al., 2019). Such observations may suggest that rather than completely employing an endurance or evasion strategy, plants can finely tune elements from these two strategies in order to contain the advance of a specific pathogen. For example, host control over timing and localization of ROS burst can be used to counteract pathogens of different classes, including necrotrophs in their early infection stages (Małolepsza \& Urbanek 2002; Seifi et al., 2013b; Unger et al., 2005).

\subsection{Other modalities for GABA to affect ROS homeostasis during biotic stress}

Besides the importance of the GABA shunt and the suspected contribution of GABA signaling, ROS homeostasis can be influenced indirectly by GABA through the action of PA. As mentioned before, GABA can be synthetized via PA catabolism, however this pathway yields also $\mathrm{H}_{2} \mathrm{O}_{2}$, which on the one hand can have detrimental effects on the plant cell structures, but on the other hand can act as a signal that activates antioxidant responses (Gupta et al., 2016). A role for PA in boosting antioxidant 
defenses under different stresses has been widely described (Minocha et al., 2014, and references therein), and a study demonstrated that PA can directly modulate gene expression of CAT in the green microalga Ulva fasciata, suggesting potential signaling roles (Sung et al., 2011). Accordingly, PA involvement in the modulation of ROS accumulation during plant-pathogen interactions has been reported (Lou et al., 2016; Seifi \& Shelp, 2019). Catabolism of the polyamine spermine (Spm) was proven to contribute to the onset of HR in tobacco and cotton (Gossipium hirsutum L.), while exogenous Spm treatment resulted in the activation of transcription factors involved in the $\mathrm{H}_{2} \mathrm{O}_{2}$ signaling pathway in the Arabidopsis-cucumber mosaic virus pathosystem (Mo et al., 2015; Yoda et al., 2003). In line with this, inhibition of putrescine (Put) catabolism through Put acetylation decreased $\mathrm{H}_{2} \mathrm{O}_{2}$ production during $\mathrm{HR}$ in Arabidopsis, resulting in the suppression of microbial defenses against P. syringae DC3000 (Lou et al., 2016). Given that GABA appears to be critical in regulating antioxidant mechanisms during stress conditions (Seifi et al., 2013b; Song et al., 2010; Wang et al., 2017), PA catabolism-dependent accumulation of both $\mathrm{H}_{2} \mathrm{O}_{2}$ and $\mathrm{GABA}$ can provide further layers of regulation in the context of ROS dynamics under stress conditions (Gupta et al., 2016). Because of such considerations and the tight connection between GABA and PA during abiotic and biotic stress conditions (Hatmi et al., 2015; Podlešáková et al., 2019; Wang et al., 2014), it is tempting to speculate that the modulation of the fluxes between GABA and PA metabolic pathways represents a way for controlling ROS accumulation and signaling during plant-pathogen interactions. Besides the metabolic link to $\mathrm{PA}, \mathrm{GABA}$ can be preferably catabolized to GHB under elevated NADH/NAD ${ }^{+}$ratio conditions, which can take place under stresses such as cold, anoxia and drought (Allan et al., 2003, 2008; Kaplan et al., 2007). A positive role was suggested for GHB in counteracting excessive ROS accumulation under stress conditions by supplying reductive equivalents in the form of NADPH by the action of the GHBDH (Breitkreuz et al., 2003). NADPH is required for the ascorbate/glutathione cycle enzymes and other detoxifying enzymes, and thus cytosolic enzymes able to regenerate NADPH are considered as a secondary defense system (Signorelli et al., 2013). Moreover, GABA catabolism into GHB was proposed to contribute to regulating ROS homeostasis in tomato (Bao et al., 2015). However, there are no links between GHB metabolism and modulation of ROS homeostasis during plant-pathogen interactions (Shelp et al., 2017). Finally, the previously discussed link between GABA and ET can provide a further way to control ROS homeostasis during pathogen attack, given the regulatory role exerted by ET over pathogen-induced ROS burst (Mersmann et al., 2010; Zhang, 2015) and autophagy 
(Shibuya et al., 2013). Autophagy is a highly regulated process aimed to the recycling of cellular components and has been recently proposed to contribute to the bulk clearance of ROS excesses during both biotic and abiotic stress conditions (Signorelli et al., 2019). It will be interesting to direct future research to elucidate the eventual contribution of autophagic processes to endurance strategies during plant-pathogen interactions (Kabbage et al., 2013; Zhou et al., 2018).

\section{Interconnections between GABA and other stress-related amino acids}

So far, the findings discussed here highlighted how GABA can contribute to plant defenses through signaling, energy supply and control of the ROS homeostasis. Besides GABA, there are other amino acids reported to play relevant roles in plant immunity (Seifi et al., 2013a; Thevenet et al., 2016; Zeier, 2013). Their relations with GABA and main recent findings about them are discussed below.

\subsection{6-aminobutyric acid}

BABA is a non-proteinogenic amino acid and isomer of GABA, known to boost defense responses against a wide array of pathogens in several plant species, such as Arabidopsis, lettuce and grape (Cohen et al., 2010; Hamiduzzaman et al., 2005; Ton et al., 2007). As GABA, it is a non-proteinogenic amino acid. BABA is perceived by plant cells in a very peculiar way: it specifically binds to the active site of aspartyl-tRNA synthetase, determining the intracellular accumulation of aspartate (Asp) and uncharged t-RNA. Such events trigger a signaling cascade that results in the activation of both SAdependent and independent pathways, and prime plants against both biotrophs and necrotrophs (Baccelli \& Mauch-Mani, 2016; Luna et al., 2014; Zimmerli et al., 2000). Furthermore, BABA priming affects the methylome of plants, resulting in a transcriptional memory of the event which can affect following generations (Kuźnicki et al., 2019). Recent studies showed how BABA perception reshapes the primary metabolism of plant cells by boosting the TCA cycle and mobilizing starch reservoirs towards callose synthesis and deposition at the infection sites (Gamir et al., 2018; Pastor et al., 2014; Yao et al., 2019).

Recent, BABA was believed to be a xenobiotic compound for plants. However, a study by Thevenet and colleagues demonstrated unequivocally that BABA can be synthetized in plants in response to stress (Thevenet et al., 2016). Such finding opens the question on how BABA is synthetized in plants. A previous report in bacteria suggested that BABA might be synthesized from Glu, as suggested for 
the biosynthetic pathway of the antibiotic incednine, however, such hypothesis await to be confirmed in plants (Takaishi et al., 2012; Thevenet et al., 2016). If Glu is not the main precursor of BABA in plants, it remains possible that it may be originated from GABA or AABA ( $\alpha$-aminobutyric acid), the two most similar compounds to BABA available in plant cells, by a so far unknown mechanism (Figure 2). However, such hypothesis awaits further investigation. On the other hand, BABA-dependent stimulation of TCA activity may ultimately result in higher intracellular levels of Glu due to increased accumulation of $\alpha$-ketoglutaric acid in the mitochondria which can be further converted to Glu through transamination (Figure 2) (Pastor et al., 2014). This, together with the $\mathrm{Ca}^{+2}$ influx that occurs following pathogen perception, can give an additional boost to GABA accumulation in attacked cells.

\subsection{Glutamate}

Given the importance of primary metabolism in arming the plant defensive arsenal, it is not surprising that amino acids with important roles in N assimilation, such as the ones of the GS/GOGAT cycle, were reported to influence immune responses in different pathosystems (Brauc et al., 2011; Kadotani et al., 2016). As mentioned before, Glu originated from the GS/GOGAT cycle is the main precursor for GABA biosynthesis. Glu itself, however, is a major metabolic hub that links $\mathrm{C}$ metabolism, $\mathrm{N}$ metabolism and redox balance, thus influencing host capacity to resist a pathogen by altering $\mathrm{C}$ and $\mathrm{N}$ availability at the infection site (Dulermo et al., 2009; Seifi et al., 2013a). Besides metabolic adjustments, an important role for the ionotropic glutamate receptor (iGluR)-like channels in transducing defense signals was recently demonstrated. Following Microbe-Associated Molecular Patterns (MAMP) perception, Glu was suggested to promote the opening of iGluRs to allow $\mathrm{Ca}^{+2}$ influx from the apoplast and in this way activate the mitogen-activated protein kinases (MAPKs) signaling pathway (Kwaaitaal et al., 2011). A number of homologs of animal iGluRs were so far identified in different plant species, and are classified into three clades (Weiland et al., 2016). Downregulation of clade III GLUTAMATE RECEPTOR-LIKE genes was shown to lead to increased susceptibility to $B$. cinerea in Arabidopsis, while knockout of AtiGluR3.1, 3.2, 3.3 or AtiGluR3.6 decreases the depolarizing capacity of membranes following wounding and the expression of JAZ10, a gene involved in the JA pathway (Mousavi et al. 2013). Consistent with this line of evidence, recent research demonstrated that exogenous Glu treatment can decrease susceptibility of Arabidopsis roots towards $P$. syringae DC3000 and the fungal pathogen Colletotrichium higginsianum, and that such primed state is transmitted from roots to distal leaves (Goto et al., 2019). Interestingly, such resistance was shown to be accompanied by increased 
expression on defense genes related to the perception of PAMPs damage-associated molecular patterns (DAMPs), although with a slower timing than what observed for classic elicitors such as the bacterial peptide flg22 (Goto et al., 2019).

It was also shown that Glu can activate nitric oxide $(\bullet \mathrm{NO})$ production, a gasotransmitter with several roles in coordinating immune responses (Bellin et al., 2013; Vatsa et al., 2011). However, the authors noted that $\bullet N O$ production was not followed by typical downstream responses such as ROS accumulation and MAPK activation, leaving open the question concerning the biological significance of such •NO increase (Vatsa et al., 2011). In light of this body of evidence, we propose that the GluGABA hub can be seen as a critical node to control the traffic of metabolic resources during biotic stress responses (Figure 2). Moreover, given that both GABA and Glu are able to specifically bind ionotropic receptors in plants, coordinating spatiotemporal dynamics of these amino acids might be important to activate long-distance stress responses vehiculated by electric signals (Weiland et al., 2016; Toyota et al., 2018). In this perspective, GABA and Glu constitute an interface between metabolic adjustments and signaling in the plant stress physiology context (Michaeli \& Fromm, 2015; Kan et al., 2017).

\subsection{Proline}

Like GABA, Pro is mainly synthesized from Glu and its metabolism is also known to be activated under stress conditions (Signorelli \& Monza, 2017). In the mitochondria, Pro can be converted into Glu by two enzymatic reactions catalyzed by proline dehydrogenase (ProDH) and P5C reductase (P5CR) (Trovato et al., 2019). The resulting Glu can be converted to GABA by GDH activity, closing a metabolic link between Pro and GABA (Figure 2). Moreover, we previously suggested that, under stress conditions, Pro can be converted into GABA through two non-enzymatic reactions followed by the action of pyrroline dehydrogenase (PyrrDH) (Signorelli et al., 2015). The involvement of Pro in immune responses has been documented (Fabro et al., 2004; Qamar et al., 2015). Especially Pro catabolism appears to have a significant contribution in this sense since ProDH genes, $\mathrm{ProDH} 1$ and $\mathrm{ProDH} 2$ were shown to be required for the full activation of immune responses against both necrotrophs and hemibiotrophs in Arabidopsis (Rizzi et al., 2017). Furthermore, increases in pyrroline-5-carboxylate (P5C), the intermediate product of Pro metabolism (Figure 2), were shown to be correlated with ROS accumulation and the onset of HR (Senthil-Kumar \& Mysore, 2012). However, it is not clear yet 
whether the ROS produced by Pro catabolism or P5C itself is responsible for the beneficial effect of proline catabolism under biotic stress.

\section{Conclusions and future perspectives}

Recent investigations on the interface between signaling and primary metabolism are starting to reveal which metabolic adjustments are adopted by plants to cope with stresses. Regulation of GABA metabolism is emerging as one of the most important features used by plants to respond to several types of biotic interactions, thanks to its capacity to fuel cellular metabolic processes and control pathogen-induced ROS accumulation. Thus, a more comprehensive understanding of the role of GABA in plant immunity can lead to the development of effective and sustainable pest control strategies, however, important gaps of knowledge remain to be filled in this sense, such as the contribution of GABA signaling to plant immune networks and ROS balance, and the exact nature of the connection between GABA and ET biosynthesis and signaling events. Finally, a better understanding of the metabolic fluxes coordinating the accumulation of GABA and other stress-related amino acids such as Glu and Pro is needed to build a clearer picture of the role of primary metabolism in plant immunity.

\section{v. Acknowledgements}

\section{vi. References}

Al-Quraan N.A. (2015). GABA shunt deficiencies and accumulation of reactive oxygen species under UV treatments : insight from Arabidopsis thaliana calmodulin mutants. Acta Physiologiae Plantarum $37(4), 86$.

Allan W.L., Simpson J.P., Clark S.M. \& Shelp B.J. (2008). -Hydroxybutyrate accumulation in Arabidopsis and tobacco plants is a general response to abiotic stress : putative regulation by redox balance and glyoxylate reductase isoforms. J of Experimental Botany 59(9), 2555-2564.

Allan W.L., Smith R.W. and Shelp B.J. (2003). Direct Measurement of $\gamma$ - Hydroxybutyrate ( GHB ) in Crude Plant Extracts by Liquid Chromatography / Negative Ion Electrospray- Mass Spectrometry Application. Application Bulletin AB-0015, Agilent Technologies, Mississauga, Canada. 
Aloisi I., Cai G., Serafini-Fracassini D. \& Del Duca S. (2016). Polyamines in Pollen: From Microsporogenesis to Fertilization. Frontiers in Plant Science 7(2): 155.

Baccelli I. \& Mauch-Mani B. (2016). Beta - aminobutyric acid priming of plant defense: the role of ABA and other hormones. Plant Molecular Biology 91(6), 703-711.

Bao H., Chen X., Lv S., Jiang P., Feng J., Fan P., Nie L. \& Li Y. (2015). Virus-induced gene silencing reveals control of reactive oxygen species accumulation and salt tolerance in tomato by $\gamma$ aminobutyric acid metabolic pathway. Plant, Cell and Environment 38(3), 600-613.

Barbosa J.M., Singh N.K., Cherry J.H. \& Locy R.D. (2010). Nitrate uptake and utilization is modulated by exogenous $\gamma$-aminobutyric acid in Arabidopsis thaliana seedlings. Plant Physiology and Biochemistry 48(6), 443-450.

Barragan A., Weidner J.M., Jin Z., Korpi E.R. \& Birnir B. (2015). GABAergic signalling in the immune system. Acta Physiologica (Oxford) 213(4), 819-27.

Baum G., Lev-yadun S., Fridmann Y., Arazi T., Katsnelson H., Zik M. \& Fromm H. (1996). Calmodulin binding to glutamate decarboxylase is required for regulation of glutamate and GABA metabolism and normal development in plants. EMBO Journal 15(12), 2988-2996.

Bellin D., Asai S., Delledonne M. \& Yoshioka H. (2013). Nitric oxide as a mediator for defense responses. Molecular Plant Microbe Interactions 26(6), 271-7.

Bigeard J., Colcombet J. \& Hirt H. (2015). Signaling mechanisms in pattern-triggered immunity (PTI). Molecular Plant 8(4), 521-539.

Bitrián M., Zarza X., Altabella T., Tiburcio AF. \& Alcázar R. (2012). Polyamines under abiotic stress: Metabolic crossroads and hormonal crosstalks in plants. Metabolites 2(3), 516-528.

Bolton M.D., Kolmer J.A., Xu W.W. \& Garvin D.F. (2008). Lr34 -Mediated Leaf Rust Resistance in Wheat : Transcript Profiling Reveals a High Energetic Demand Supported by Transient Recruitment of Multiple Metabolic Pathways. Molecular Plant Microbe Interactions 2(3), 1515-1527.

Bouche N., Fait A., Bouchez D., Moller S.G. \& Fromm H. (2003). Mitochondrial succinic-semialdehyde 
dehydrogenase of the $\gamma$-aminobutyrate shunt is required to restrict levels of reactive oxygen intermediates in plants. Procedures of the National Academy of Sciences USA 100(11), 6843-6848.

Bown A.W., Hall D.E. \& Macgregor K.B. (2002). Insect Footsteps on Leaves Stimulate the Accumulation of 4-Aminobutyrate and Can Be Visualized through Increased Chlorophyll Fluorescence and Superoxide. Plant Physiology 129(4), 1430-1434.

Bown A.W. \& Shelp B.J. (2016). Plant GABA: Not Just a Metabolite. Trends in Plant Science 21(10), 811-813.

Brauc S., De Vooght E., Claeys M., Höfte M. \& Angenon G. (2011). Influence of over-expression of cytosolic aspartate aminotransferase on amino acid metabolism and defence responses against Botrytis cinerea infection in Arabidopsis thaliana. Journal of Plant Physiology 168(15), 1813-1819.

Breitkreuz K.E., Allan W.L., Van Cauwenberghe O.R., Jakobs C., Talibi D., Andre B. \& Shelp B.J. (2003). A Novel $p$-Hydroxybutyrate Dehydrogenase: identification and expression of an Arabidopsis cDNA and potential role under oxygen deficiency. Journal of Biological Chemistry 278(42): 41552-41556.

Broekgaarden C., Caarls L., Vos I.A., Pieterse C.M.J. \& Van Wees S.C.M. (2015). Ethylene: traffic controller on hormonal crossroads to defense. Plant Physiology 169(4), 2371-2379.

Casida J.E. \& Durkin K.A. (2015). Novel GABA receptor pesticide targets. Pesticides Biochemistry and Physiology 121(11), 22-30.

Chebib M. \& Johnston G.A.R. (1999). The ' ABC' of GABA receptors: a brief review. Clinical Experimental Pharmacology and Physiology 26(11), 937-940.

Chevrot R., Rosen R., Haudecoeur E., Cirou A., Shelp B.J., Ron E. \& Faure D. (2006). GABA controls the level of quorum-sensing signal in Agrobacterium tumefaciens. Procedures of the National Academy of Sciences USA 103(19), 7460-7464.

Cohen Y., Rubin A.E. \& Kilfin G. (2010). Mechanisms of induced resistance in lettuce against Bremia lactucae by DL- $\beta$-amino-butyric acid (BABA) European Journal of Plant Pathology 126(4), 553-573.

Cook D.E., Mesarich C.H. \& Thomma B.P.H.J. (2015). Understanding Plant Immunity as a Surveillance System to Detect Invasion. Annual Reviews of Phytopathology 53, 541-563. 
Copley T.R., Aliferis K.A., Kliebenstein D.J. \& Jabaji S.H. (2017). An integrated RNAseq- 1 H NMR metabolomics approach to understand soybean primary metabolism regulation in response to Rhizoctonia foliar blight disease. BMC Plant Biology 17(1), 84.

De la Torre F., Gutierrez-Beltran E., Pareja-Jaime Y., Chakravarthy S., Martin G.B. \& del Pozo O. (2013). The tomato calcium sensor CBL10 and its interacting protein kinase CIPK6 define a signaling pathway in plant immunity. Plant Cell 25(7), 2748-2764.

Dulermo T., Rascle C., Chinnici G., Gout E., Bligny R. \& Cotton P. (2009). Dynamic carbon transfer during pathogenesis of sunflower by the necrotrophic fungus Botrytis cinerea: From plant hexoses to mannitol. New Phytologist 183(4), 1149-1162.

Elliott K.A.C. \& Jasper H.H. (1959). Gamma-aminobutyric acid. Physiological Reviews 39(2), 383-406. Engelsdorf T., Horst R.J., Prols R., Proschel M., Dietz F., Huckelhoven R. \& Voll L.M. (2013). Reduced Carbohydrate Availability Enhances the Susceptibility of Arabidopsis toward Colletotrichum higginsianum. Plant Physiology 162(1), 225-238.

Fabro G., Kovács I., Pavet V., Szabados L. \& Alvarez M.E. (2004). Proline Accumulation and AtP5CS2 Gene Activation Are Induced by Plant-Pathogen Incompatible Interactions in Arabidopsis. Molecular Plant Microbe Interactions 17(4), 343-350.

Fait A., Fromm H., Walter D., Galili G. \& Fernie A.R. (2008). Highway or byway: the metabolic role of the GABA shunt in plants. Trends in Plant Science 13(1), 14-19.

Fait A., Yellin A. \& Fromm H. (2005). GABA shunt deficiencies and accumulation of reactive oxygen intermediates: Insight from Arabidopsis mutants. FEBS Letters 579(2), 415-420.

Feehily C., Karatzas K.A.G. (2012). Role of glutamate metabolism in bacterial responses towards acid and other stresses. Journal of Applied Microbiology 114(1), 11-24.

Flores H.E. \& Filner P. (1985). Polyamine catabolism in higher plants: Characterization of pyrroline dehydrogenase. Plant Growth Regulation 3(3), 277-291.

Forde B.G. \& Lea P.J. (2007). Glutamate in plants : metabolism, regulation , and signalling. Journal of Experimental Botany 58(9), 2339-2358. 
Forlani G., Bertazzini M. \& Giberti S. (2014). Differential accumulation of $\gamma$-aminobutyric acid in elicited cells of two rice cultivars showing contrasting sensitivity to the blast pathogen. Plant Biology (Stuttgart) 16(6), 1127-1132.

Galston A.W. \& Sawhney R.K. (1990). Polyamines in Plant Physiology. Plant Physiology 94(2), 406410.

Gamir J., Pastor V., Sánchez-Bel P., Agut B., Mateu D., García-Andrade J. \& Flors V (2018). Starch degradation, abscisic acid and vesicular trafficking are important elements in callose priming by indole-3-carboxylic acid in response to Plectosphaerella cucumerina infection. Plant Journal 96(3), $518-531$.

Gou Z.H., Wang X. \& Wang W. (2012). Evolution of neurotransmitter gamma-aminobutyric acid, glutamate and their receptors. Dongwuxue Yanjiu 33(5), 75-81.

Govrin E.M. \& Levine A. (2000). The hypersensitive response facilitates plant infection by the necotrophic pathogen Botrytis cinerea. Current Biology 10(13), 751-757.

Goto Y., Maki N., Ichinashi Y., Kitazawa D., Igarashi D., Kadota Y. \& Shirasu K. (2019). Exogenous treatment with glutamate induces immune responses in Arabidopsis. Molecular Plant Microbe Interactions. DOI:/10.1094/MPMI-09-19-0262-R

Gupta K., Sengupta A., Chakraborty M. \& Gupta B. (2016). Hydrogen Peroxide and Polyamines Act as Double Edged Swords in Plant Abiotic Stress Responses. Frontiers in Plant Science 7(9), 1343.

Hamiduzzaman M.M., Jakab G., Barnavon L., Neuhaus J.M. \& Mauch-Mani B. (2005). betaAminobutyric acid-induced resistance against downy mildew in grapevine acts through the potentiation of callose formation and jasmonic acid signaling. Molecular Plant Microbe Interactions 18(8), 819-829.

Hatmi S., Gruau C., Trotel-Aziz P., Villaume S., Rabenoelina F., Baillieul F., Eullaffroy P., Clément C., Ferchichi A. \& Aziz A. (2015). Drought stress tolerance in grapevine involves activation of polyamine oxidation contributing to improved immune response and low susceptibility to Botrytis cinerea. 
Journal of Experimental Botany 66(3), 775-787.

Heat M.C. (2000). Hypersensitive response-related death. Plant Molecular Biology 44(3), 321-334.

Hijaz F., Nehela Y. \& Killiny N. (2018). Application of gamma-aminobutyric acid increased the level of phytohormones in Citrus sinensis. Planta 248(4), 909-918.

Hua M.D., Kumar R.S., Shyur L. \& Cheng Y. (2017). Metabolomic compounds identified in Piriformospora indica -colonized Chinese cabbage roots delineate symbiotic functions of the interaction. Scientific Reports 7(1), 1-14.

Irving S.N., Osborne M.P. \& Wilson R.G. (1979). Studies on L-glutamate in insect hemolymph. I. Effect of injected L-glutamate. Physiology and Entomology 4(3), 139-146.

Ishiyama K., Inoue E., Watanabe-Takahashi A., Obara M., Yamaya T. \& Takahashi H. (2004). Kinetic Properties and Ammonium-dependent Regulation of Cytosolic Isoenzymes of Glutamine Synthetase in Arabidopsis. Journal of Biological Chemistry 279(16), 16598-16605.

Jespersen D., Yu J. \& Huang B. (2015). Metabolite Responses to Exogenous Application of Nitrogen, Cytokinin, and Ethylene Inhibitors in Relation to Heat- Induced Senescence in Creeping Bentgrass. PloS One 10(3), e0123744.

Jones J.D.G. \& Dangl J.L. (2006). The plant immune system. Nature 444(7117), 323-329.

Kabbage M., Williams B. \& Dickman M.B. (2013). Cell Death Control: The Interplay of Apoptosis and Autophagy in the Pathogenicity of Sclerotinia sclerotiorum. PLoS Pathogens 9(4), e1003287.

Kadotani N., Akagi A., Takatsuji H., Miwa T. \& Tagarashi D. (2016). Exogenous proteinogenic amino acids induce systemic resistance in rice. BMC Plant Biology 16(3), 60.

Kalhor M.S., Aliniaeifard S., Seif M., Asayesh E.J., Bernard F., Hassani B. \& Li T. (2018). Enhanced salt tolerance and photosynthetic performance: Implication of $\gamma$-amino butyric acid application in saltexposed lettuce (Lactuca sativa L.) plants. Plant Physiology and Biochemistry 130(9), 157-172. 
Kan C.C., Chung T.Y., Wu H.Y., Juo Y.A. \& Hsieh M.H. (2017). Exogenous glutamate rapidly induces the expression of genes involved in metabolism and defense responses in rice roots. BMC Genomics 18(1), 186.

Kaplan F., Kopka J., Sung D.Y., Zhao W., Popp M., Porat R., Guy C.L., Mol P., Program C.B. \& Dagan B. (2007). Transcript and metabolite profiling during cold acclimation of Arabidopsis reveals an intricate relationship of cold-regulated gene expression with modifications in metabolite content. Plant Journal 50(6), 967-981.

Kathiresan A., Tung P., Chinnappa C.C. \& Reid D.M. (1997). y-Aminobutyric Acid Stimulates Ethylene Biosynthesis in Sunflower. Plant Physiology 115(1), 129-135.

Kathiresan A., Miranda J., Chinnappa C.C. \& Reid D.M. (1998). -aminobutyric acid promotes stem elongation in Stellaria longipes: The role of ethylene Plant Growth Regulation 26(2), 131-137.

Kim H., Kashima Y., Ishikawa K. \& Yamano N. (2014). Purification and Characterization of the First Archaeal Glutamate Decarboxylase from Pyrococcus horikoshii. Bioscience, Biotechnology and Biochemistry 73(1), 224-227.

Kim N.H., Kim B.S. \& Hwang B.K. (2013). Pepper Arginine Decarboxylase Is Required for Polyamine and -Aminobutyric Acid Signaling in Cell Death and Defense Response. Plant Physiology 162(4), 2067-2083.

Kinnersley A.M. \& Turano F.J. (2000). Gamma aminobutyric acid (GABA) and plant responses to stress. CRC Critical Reviews in Plant Science 19(6), 479-509.

Kraepiel Y. \& Barny M. (2015). Gram-negative phytopathogenic bacteria , all hemibiotrophs after all? Molecular Plant Pathology 17(3), 313-316.

Kuźnicki, D., Meller, B., Arasimowicz-Jelonek, M., Braszewska-Zalewska, A., Drozda, A., \& FloryszakWieczorek, J. (2019). BABA-Induced DNA Methylome Adjustment to Intergenerational Defense Priming in Potato to Phytophthora infestans. Frontiers in Plant Science DOI: 10.3389/fpls.2019.00650. 
Kwaaitaal M., Huisman R., Maintz J., Reinstädler A. \& Panstruga R. (2011). lonotropic glutamate receptor (iGluR)-like channels mediate MAMP-induced calcium influx in Arabidopsis thaliana. Biochemistry Journal 440(3), 355-373.

Lancien M. \& Roberts M.R. (2006). Regulation of Arabidopsis thaliana 14-3-3 gene expression by Yaminobutyric acid. Plant, Cell and Environment 29(7), 1430-1436.

Lang J., Gonzalez-mula A., Taconnat L., Clement G. \& Faure D. (2015). The plant GABA signaling downregulates horizontal transfer of the Agrobacterium tumefaciens virulence plasmid. New Phytologist 210(3), 974-983.

Li W., Liu J., Ashraf U., Li G., Li Y., Lu W., Gao L., Han F. \& Hu J. (2016). Exogenous Y-aminobutyric Acid (GABA) Application Improved Early Growth, Net Photosynthesis, and Associated PhysioBiochemistryical Events in Maize. Frontiers in Plant Science 7(6), 919.

Liu G., Ji Y., Bhuiyan N.H., Pilot G., Selvaraj G., Zou J. \& Wei Y. (2010). Amino Acid Homeostasis Modulates Salicylic Acid - Associated Redox Status and Defense Responses in Arabidopsis. Plant Cell 22(11), 3845-3863.

Liu H., Coulthurst S.J., Pritchard L., Hedley P.E., Ravensdale M., Burr T., Takle G., Brurberg M., Birch P.R.J., Salmond G.P.C., et al (2008). Quorum Sensing Coordinates Brute Force and Stealth Modes of Infection in the Plant Pathogen Pectobacterium atrosepticum. PLoS Pathogens 4(6), e1000093.

Liu J.H., Wang W., Wu H., Gong X. \& Moriguchi T. (2015). Polyamines function in stress tolerance: from synthesis to regulation. Frontiers in Plant Science 6(10), 827.

Lou Y.R., Bor M., Yan J., Preuss A.S. \& Jander G. (2016). Arabidopsis NATA1 acetylates putrescine and decreases defense-related hydrogen peroxide accumulation. Plant Physiology 171(2), 1443-1455.

Ma Y., Walker R.K., Zhao Y. \& Berkowitz G.A. (2012). Linking ligand perception by PEPR pattern recognition receptors to cytosolic $\mathrm{Ca}^{2+}$ elevation and downstream immune signaling in plants. Procedures of the National Academy of Sciences USA 109(48), 19852-19857.

MacGregor K.B., Shelp B.J., Peiris S. \& Bown A.W. (2003). Overexpression of glumatate decarboxylase in transgenic tobacco plants deters feeding by phytophagous insect larvae. Journal of 
Chemistry and Ecology 29(9), 2177-2182.

Mahmud J.A.L., Hasanuzzaman M., Nahar K., Rahman A., Hossain S. \& Fujita M. (2017). $\gamma$ aminobutyric acid ( GABA ) confers chromium stress tolerance in Brassica juncea $\mathrm{L}$. by modulating the antioxidant defense and glyoxalase systems. Ecotoxicology 26(5), 675-690.

Majumdar R., Minocha R., Lebar M.D., Rajasekaran K., Long S., Carter-Wientjes C., Minocha S. \& Cary J.W. (2019). Contribution of Maize Polyamine and Amino Acid Metabolism Toward Resistance Against Aspergillus flavus Infection and Aflatoxin Production. Frontiers in Plant Science 10(5), 692.

Małolepsza U. \& Urbanek H. (2002). O-hydroxyethylorutin-mediated enhancement of tomato resistance to Botrytis cinerea depends on a burst of reactive oxygen species. Journal of Phytopathology 150(11), 616-624.

Mccraw S.L., Park D.H., Jones R., Bentley M.A., Rico A., Ratcliffe R.G., Kruger N.J., Collmer A. \& Preston G.M. (2016). GABA ( $\gamma$-Aminobutyric Acid ) Uptake Via the GABA Permease GabP Represses Virulence Gene Expression in Pseudomonas syringae pv . tomato DC3000. Molecular Plant Microbe Interactions 29(12), 938-949.

Mclean M.D., Yevtushenko D.P., Deschene A., Van O.R., Makhmoudova A., Potter J.W., Bown A.W. \& Barry J. (2003). Overexpression of glutamate decarboxylase in transgenic tobacco plants confers resistance to the northern root-knot nematode. Molecular Breeding 11(4), 277-285.

Mersmann S., Bourdais G., Rietz S. \& Robatzek S. (2010). Ethylene Signaling Regulates Accumulation of the FLS2 Receptor and Is Required for the Oxidative Burst Contributing to Plant Immunity. Plant Physiology 154(1), 391-400.

Michaeli S., Fait A., Lagor K., Nunes-nesi A., Grillich N., Yellin A., Bar D., Khan M., Fernie A.R., Turano F.J., et al (2011). A mitochondrial GABA permease connects the GABA shunt and the TCA cycle, and is essential for normal carbon metabolism. Plant Journal 67(3), 485-498.

Michaeli S. \& Fromm H. (2015). Closing the loop on the GABA shunt in plants: are GABA metabolism and signaling entwined? Frontiers in Plant Science 6(6), 419.

Miller R.N., Costa Alves G.S. \& Van Sluys M.A. (2017). Plant immunity: unravelling the complexity of 
plant responses to biotic stresses. Annals of Botany 119(5), 681-687.

Minocha R., Majumdar R. \& Minocha S.C. (2014). Polyamines and abiotic stress in plants: a complex relationship. Frontiers in Plant Science 5(5), 175.

Mo H., Wang X., Zhang Y., Zhang G., Zhang J. \& Ma Z. (2015). Cotton polyamine oxidase is required for spermine and camalexin signalling in the defence response to Verticillium dahliae. Plant Journal 83(6), 962-975.

Mousavi S.A.R., Chauvin A., Pascaud F, Kellenberger S. \& Farmer E.E. (2013). Glutamate receptor-like genes mediate leaf-to-leaf wound signalling. Nature 500(7463), 422-426.

Nasr Esfhani M., Kusano M., Huu K., Watanabe Y., Ha C. \& Saito K. (2016). Adaptation of the symbiotic Mesorhizobium-chickpea relationship to phosphate deficiency relies on reprogramming of whole-plant metabolism. Procedures of the National Academy of Sciences USA 113(32), 4610-4619.

O'Leary B.M., Neale H.C., Geilfus C.M., Jackson R.W., Arnold D.L. \& Preston G.M. (2016). Early changes in apoplast composition associated with defence and disease in interactions between Phaseolus vulgaris and the halo blight pathogen Pseudomonas syringae Pv. phaseolicola. Plant, Cell and Environment 39(10), 2172-2184.

Oldroyd G.E.D., Engstrom E.M. \& Long S.R. (2001). Ethylene Inhibits the Nod Factor Signal Transduction Pathway of Medicago truncatula. Plant Cell 13(8), 1835-1849.

Oliveira I.C. \& Coruzzi G.M. (1999). Carbon and Amino Acids Reciprocally Modulate the Expression of Glutamine Synthetase in Arabidopsis. Plant Physiology 121(1), 301-309.

Palanivelu R., Brass L., Edlund A.F. \& Preuss D. (2003). Pollen Tube Growth and Guidance Is Regulated by POP2 , an Arabidopsis Gene that Controls GABA Levels. Cell 114(1), 47-59.

Park D.H., Mirabella R., Bronstein P.A., Preston G.M., Haring M.A., Lim C.K., Collmer A. \& Schuurink R.C. (2010). Mutations in $\gamma$-aminobutyric acid ( GABA ) transaminase genes in plants or Pseudomonas syringae reduce bacterial virulence. Plant Journal 64(2), 318-330. 
Pastor V., Balmer A., Gamir J., Flors V. \& Mauch-Mani B. (2014). Preparing to fight back: generation and storage of priming compounds. Frontiers in Plant Science 5(6), 295.

Pieterse C.M.J., Van der Does D., Zamioudis C., Leon-Reyes A. \& Van Wees S.C.M. (2012). Hormonal Modulation of Plant Immunity. Annual Review of Cell and Developmental Biology 28, 489-521.

Planamente S., Mondy S., Hommais F., Vigouroux A., Moréra S. \& Faure D. (2012). Structural basis for selective GABA binding in bacterial pathogens. Molecular Microbiology 86(5), 1085-1099.

Podlešáková K., Ugena L., Spíchal L., Dole K. \& De Diego N. (2019). Phytohormones and polyamines regulate plant stress responses by altering GABA pathway. New Biotechnology 48(1), 53-65.

Qamar A., Mysore K.S. \& Senthil-Kumar M. (2015). Role of proline and pyrroline-5-carboxylate metabolism in plant defense against invading pathogens. Frontiers in Plant Science 6(6), 503.

Ramesh S.A., Tyerman S.D., Xu B., Bose J., Kaur S., Conn V., Domingos P., Ullah S., Wege S., Shabala S., et al. (2015). GABA signalling modulates plant growth by directly regulating the activity of plantspecific anion transporters. Nature Communications 6, 8293.

Ramputh A. \& Shelp A.W. (1996). Rapid y-Aminobutyric Acid Synthesis and the Inhibition of the Growth and Development of Oblique-Banded Leaf-Roller Larvae. Plant Physiology 111(4), 1349-1352.

Reyes-Darias J.A., García V., Rico-Jiménez M., Corral-Lugo A., Lesouhaitier O., Juárez-Hernández D., Yang Y., Bi S., Feuilloley M., Muñoz-Rojas J., Sourjik V. \& Krell T. (2015). Specific gamma-

aminobutyrate chemotaxis in pseudomonads with different lifestyle. Molecular Microbiology 97(3), 488-501.

Rico A. \& Preston G.M. (2008). Pseudomonas syringae pv . tomato DC3000 Uses Constitutive and Apoplast-Induced Nutrient Assimilation Pathways to Catabolize Nutrients That Are Abundant in the Tomato Apoplast. Molecular Plant Microbe Interactions 21(2), 269-282.

Rojas C.M., Senthil-Kumar M., Tzin V. \& Mysore K.S. (2014). Regulation of primary plant metabolism during plant-pathogen interactions and its contribution to plant defense. Frontiers in Plant Science 
$5(2), 17$.

Scholz S.S., Malabarba J., Reichelt M., Heyer M., Ludewig F. \& Mithöfer A. (2017). Evidence for GABA-Induced Systemic GABA Accumulation in Arabidopsis upon Wounding. Frontiers in Plant Science 8(), 1-9.

Scholz S.S., Reichelt M., Mekonnen D.W., Ludewig F. \& Mithöfer A. (2015). Insect Herbivory-Elicited GABA Accumulation in Plants is a Wound-Induced, Direct, Systemic, and Jasmonate-Independent Defense Response. Frontiers in Plant Science 6(3), 388.

Schulz P., Herde M. \& Romeis T. (2013). Calcium-dependent protein kinases: hubs in plant stress signaling and development. Plant Physiology 163(2), 523-530.

Seifi H.S., Curvers K., De Vleesschauwer D., Delaere I., Aziz A. \& Höfte M. (2013b). Concurrent overactivation of the cytosolic glutamine synthetase and the GABA shunt in the ABA-deficient sitiens mutant of tomato leads to resistance against Botrytis cinerea. New Phytologist 199(2), 490-504.

Seifi H.S., Van Bockhaven J., Angenon G. \& Höfte M. (2013a). Glutamate Metabolism in Plant Disease and Defense: Friend or Foe?. Molecular Plant Microbe Interactions 26(5), 475-485.

Seifi H.S. \& Shelp B.J. (2019). Spermine Differentially Refines Plant Defense Responses Against Biotic and Abiotic Stresses. Frontiers in Plant Science 10(2), 117.

Seifikalhor M., Aliniaeifard S., Hassani B., Niknam V. \& Lastochkina O. (2019). Diverse role of $\gamma^{\text {- }}$ aminobutyric acid in dynamic plant cell responses. Plant Cell Reports 38(8), 847-867.

Senthil-Kumar M. \& Mysore K.S. (2012). Ornithine-delta-aminotransferase and proline dehydrogenase genes play a role in non-host disease resistance by regulating pyrroline-5carboxylate metabolism-induced hypersensitive response. Plant, Cell and Environment 35(7), 132943.

Seybold H., Trempel F, Ranf S., Scheel D., Romeis T. \& Lee J. (2014). Ca ${ }^{2+}$ signalling in plant immune response: from pattern recognition receptors to $\mathrm{Ca}^{2+}$ decoding mechanisms. New Phytologist 204(4), 782-790. 
Shelp B.J., Bown A.W. \& Faure D. (2006). Extracellular Y-Aminobutyrate Mediates Communication between Plants and Other Organisms. Plant Physiology 142(4), 1350-1352.

Shelp B.J., Bozzo G.G., Trobacher C.P., Zarei A., Deyman K.L. \& Brikis C.J. (2012). Hypothesis/review: Contribution of putrescine to 4-Aminobutyrate (GABA) production in response to abiotic stress. Plant Science 193-194(9), 130-135.

Shelp B.J., Bown A.W. \& Zarei A. (2017). 4-Aminobutyrate (GABA): a metabolite and signal with practical significance. Botany 95(11), 1015-1032.

Shelp B.J. \& Zarei A. (2017). Subcellular compartmentation of 4-aminobutyrate (GABA) metabolism in arabidopsis: An update. Plant Signaling \& Behavior 12(5), e1322244.

Sheng Y., Xiao H., Guo C., Wu H. \& Wang X. (2018). Effects of exogenous gamma-aminobutyric acid on $\alpha$-amylase activity in the aleurone of barley seeds. Plant Physiology and Biochemistry 127(6), 3946.

Shibuya K., Niki T. \& Ichimura K. (2013). Pollination induces autophagy in petunia petals via ethylene. Journal of Experimental Botany 64(4), 1111-1120.

Signorelli S., Corpas F.J., Borsani O., Barroso J.B. \& Monza J. (2013). Water stress induces a differential and spatially distributed nitro-oxidative stress response in roots and leaves of Lotus japonicus. Plant Science 201-202, 137-146.

Signorelli S., Dans P.D., Coitiño E.L., Borsani O. \& Monza J. (2015). Connecting proline and $\gamma^{-}$ aminobutyric acid in stressed plants through non-enzymatic reactions. PLoS One 10(3), e0115349.

Signorelli S. \& Monza J. (2017). Identification of $\Delta 1$-pyrroline 5-carboxylate synthase (P5CS) genes involved in the synthesis of proline in Lotus japonicus. Plant Signaling and Behavior 12(11), e1367464.

Signorelli S., Tarkowski Ł.P., Van den Ende W. \& Bassham D.C. (2019). Linking Autophagy to Abiotic and Biotic Stress Responses. Trends in Plant Science 24(5), 413-430.

Snedden W.A., Arazi T., Fromm H. \& Shelp B.J. (1995). Calcium / Calmodulin Activation of Soybean Glutamate Decarboxylase. Plant Physiology 108(2), 543-549. 
Solomon P.S. \& Oliver R.P. (2002). Evidence that $\gamma$-aminobutyric acid is a major nitrogen source during Cladosporium fulvum infection of tomato. Planta 214(3), 414-420.

Song H., Xu X., Wang H. \& Tao Y. (2010). Exogenous Y -aminobutyric acid alleviates oxidative damage caused by aluminium and proton stresses on barley seedlings. Journal of the Sciences of Food and Agriculture 90(9), 1410-1416.

Steinhorst L. \& Kudla J. (2013). Calcium and reactive oxygen species rule the waves of signaling. Plant Physiology 163(2), 471-485.

Sulieman S. \& Schulze J. (2010). Phloem-derived $\gamma$-aminobutyric acid ( GABA ) is involved in upregulating nodule $\mathrm{N}_{2}$ fixation efficiency in the model legume Medicago truncatula. Plant, Cell and Environment 33(12), 2162-2172.

Sun C., Jin L., Cai Y., Huang Y., Zheng X. \& Yu T. (2019). L-Glutamate treatment enhances disease resistance of tomato fruit by inducing the expression of glutamate receptors and the accumulation of amino acids. Food Chemistry 293(9), 263-270.

Szatmari A., Zvara A., Moricz A.M., Besenyei E., Szabo E., Ott P., Puskas L.G. \& Boszo Z. (2014). Pattern Triggered Immunity (PTI) in Tobacco: Isolation of Activated Genes Suggests Role of the Phenylpropanoid Pathway in Inhibition of Bacterial Pathogens. PLoS ONE 9(8), e102869.

Takaishi M., Kudo F. \& Eguchi T. (2012). A unique pathway for the 3-aminobutyrate starter unit from L-glutamate through b-glutamate during biosynthesis of the 24- membered macrolactam antibiotic, incednine. Organic Letters 14(17), 4591-4593.

Takeuchi K. (2015). GABA, A Primary Metabolite Controlled by the Gac/Rsm Regulatory Pathway, Favors a Planktonic Over a Biofilm Lifestyle in Pseudomonas protegens CHA0. Molecular Plant Microbe Interactions 31(2), 274-282.

Tarkowski Ł.P., Van De Poel B., Höfte M. \& Van Den Ende W. (2019). Sweet Immunity : Inulin Boosts Resistance of Lettuce ( Lactuca sativa) against Grey Mold ( Botrytis cinerea) in an Ethylene- 
Dependent Manner. International Journal of Molecular Sciences 20(5), E1052.

Tauzin A.S. \& Giardina T. (2014). Sucrose and invertases, a part of the plant defense response to the biotic stresses. Frontiers in Plant Science 5(6), 293.

Thevenet D., Pastor V., Baccelli I., Balmer A., Vallat A., Neier R., Glauser G. \& Mauch-Mani B. (2017). The priming molecule $\beta$-aminobutyric acid is naturally present in plants and is induced by stress. New Phytologist 213(2), 552-559.

Ton J., Jakab G., Toquin V., Flors V., Lavicoli A., Maeder M.N., Metraux J.P. \& Mauch-Mani B. (2007). Dissecting the $\beta$-aminobutyric acid - induced priming phenomenon in Arabidopsis. Plant Cell 17(3), 987-999.

Toyota, M., Spencer, D., Sawai-Toyota, S., Jiaqi, W., Zhang, T., Koo, A.J., Howe, G.A. \& Gilroy, S. (2018). Glutamate triggers long-distance, calcium-based plant defense signaling. Science 361: 11121115.

Tripathi D. (2017). Bacterial pathogens in plants. Journal of Bacteriology \& Mycology 4(2), 38-39. Trovato M., Forlani G., Signorelli S. \& Funck D. (2019). Proline Metabolism and its Functions in Development and Stress Tolerance. In: Osmoprotectant-mediated abiotic stress tolerance in plants: recent advances and future perspectives. (eds Kumar V., Burritt DJ, Fujita M., et al.) Springer, New York.

Unger C., Kleta S., Jandl G. \& Tiedemann A.V. (2005). Suppression of the defence-related oxidative burst in bean leaf tissue and bean suspension cells by the necrotrophic pathogen Botrytis cinerea. Journal of Phytopathology 153(1), 15-26.

Vatsa P., Chiltz A., Bourque S., Wendehenne D., Garcia-Brugger A. \& Pugin A. (2011). Involvement of putative glutamate receptors in plant defence signaling and NO production. Biochimie 93(12), 20952101. 
Vijayakumari K. \& Puthur J.T. (2016). -Aminobutyric acid (GABA) priming enhances the osmotic stress tolerance in Piper nigrum Linn. plants subjected to PEG-induced stress. Plant Growth Regulation 78(1), 57-67.

von Bodman S.B., Bauer W.D. \& Coplin D.L. (2003). Quorum sensing in plant-pathogenic bacteria. Annual Review of Phytopathology 41, 455-482.

Wallace W., Secor J. \& Schrader L.E. (1984). Rapid Accumulation of y-Aminobutyric Acid and Alanine in Soybean Leaves in Response to an Abrupt Transfer to Lower Temperature, Darkness, or Mechanical Manipulation. Plant Physiology 75(1), 170-175.

Wang G., Kong J., Cui D., Zhao H., Niu Y., Xu M., Jiang G., Zhao Y. \& Wang, W. (2019). Resistance against Ralstonia solanacearum in tomato depends on the methionine cycle and the $\gamma$-aminobutyric acid metabolic pathway. Plant Journal 97(6), 1032-1047.

Wang J.W., Zheng L.P., Wu J.Y. \& Tan R.X. (2006). Involvement of nitric oxide in oxidative burst, phenylalanine ammonia-lyase activation and Taxol production induced by low-energy ultrasound in Taxus yunnanensis cell suspension cultures. Nitric Oxide 15(4), 351-358.

Wang Y., Gu W., Meng Y., Xie T., Li L., Li J. \& Wei S. (2017). Y-Aminobutyric Acid Imparts Partial Protection from Salt Stress Injury to Maize Seedlings by Improving Photosynthesis and Upregulating Osmoprotectants and Antioxidants. Scientific Reports 7, 43609.

Wang Y., Luo Z., Huang X., Yang K., Gao S. \& Du R. (2014). Effect of exogenous Y-aminobutyric acid ( GABA ) treatment on chilling injury and antioxidant capacity in banana peel. Scientia Horticulturae 168(3), 132-137.

Ward J.L., Forcat S., Beckmann M., Bennett M., Miller S.J., Baker J.M., Hawkins N.D., Vermeer C.P., Lu C., Lin W., et al. (2010). The metabolic transition during disease following infection of Arabidopsis thaliana by Pseudomonas syringae pv. tomato. Plant Journal 63(3), 443-457.

Warren C.R. (2015). Wheat roots efflux a diverse array of organic N compounds and are highly proficient at their recapture. Plant and Soil 397(7), 147-162. 
Weiland M., Mancuso S. \& Baluska F. (2016). Signalling via glutamate and GLRs in Arabidopsis thaliana. Functional Plant Biology 43(1), 1-25.

Wittek A., Dreyer I., Al-Rasheid K.A.S., Sauer N., Hedrich R. \& Geiger D. (2017). The fungal UmSrt1 and maize ZmSUT1 sucrose transporters battle for plant sugar resources. Journal of Integrative Plant Biology 59(6), 422-435.

Wu C., Zhou S., Zhang Q., Zhao W. \& Peng Y. (2006). Molecular cloning and differential expression of an gamma-aminobutyrate transaminase gene, OsGABA-T, in rice (Oryza sativa) leaves infected with blast fungus. Journal of Plant Research 119(6), 663-669.

Wu C. \& Sun D. (2015). GABA receptors in brain development, function, and injury. Metabolic Brain Diseases 30(2), 367-379.

Yang J., Sun C., Zhang Y., Fu D., Zheng X. \& Yu T. (2017). Induced resistance in tomato fruit by Y aminobutyric acid for the control of alternaria rot caused by Alternaria alternata. Food Chemistry 221(4), 1014-1020.

Yao, L., Zhong Y., Wang B., Yan J. \& Wu T. (2019). BABA application improves soybean resistance to aphid through activation of phenylpropanoid metabolism and callose deposition. Pest Management Science DOI: $10.1002 /$ ps.5526.

Yoda H., Yamaguchi Y. \& Sano H. (2003). Induction of Hypersensitive Cell Death by Hydrogen Peroxide Produced through Polyamine Degradation. Plant Physiology 132(4), 1973-1981.

Yu C., Zeng L., Sheng K., Chen F., Zhou T., Zheng X. \& Yu T. (2014). Y-Aminobutyric acid induces resistance against Penicillium expansum by priming of defence responses in pear fruit. Food Chemistry 159(9), 29-37.

Žárský V. (2015). Signal transduction: GABA receptor found in plants. Nature Plants 1, 15115.

Zeier J. (2013). New insights into the regulation of plant immunity by amino acid metabolic pathways. Plant, Cell and Environment 36(12), 2085-2103. 
Zhang Y., Xu S., Ding P., Wang D., Cheng Y.T., He J., Gao M., Xu F., Li Y., Zhu Z. et al. (2010). Control of salicylic acid synthesis and systemic acquired resistance by two members of a plant-specific family of transcription factors. Procedures of the National Academy of Sciences USA 107(42), 18220-18225.

Zhang H. (2015). Arabidopsis AtERF15 positively regulates immunity against Pseudomonas syringae pv. tomato DC3000 and Botrytis cinerea. Frontiers in Plant Science 6(9), 686.

Zhao Y., Qi Z. \& Berkowitz G.A. (2013). Teaching an old hormone new tricks: cytosolic $\mathrm{Ca}^{2+}$ elevation involvement in plant brassinosteroid signal transduction cascades. Plant Physiology 163(2), 555-565.

Zhou S., Hong Q., Li Y., Li Q. \& Wang M. (2018). Autophagy contributes to regulate the ROS levels and PCD progress in TMV-infected tomatoes. Plant Science 269, 12-19.

Zimmerli L., Jakab G., Metraux J.P. \& Mauch-Mani B. (2000). Potentiation of pathogen-specific defense mechanisms in Arabidopsis by $\beta$-aminobutyric acid. Procedures of the National Academy of Sciences USA 97(23), 12920-12925. 


\section{vii. Tables}

Table 1. Pest and pathogens species are able to induce alterations in host GABA metabolism. The table shows pest and pathogens reported to impact components of GABA metabolism and GABA levels during the interaction with the host, alongside the tissue examined and pathogen lifestyle.

\begin{tabular}{|c|c|c|c|c|c|}
\hline Pathogen/Pest & Lifestyle & Host & Tissue & Effect & Reference \\
\hline Agrobacterium tumefaciens & biotroph & Arabidopsis thaliana & Crown gall tumor & Increased GABA levels & Lang et al., 2016 \\
\hline Pseudomonas syringae & hemibiotroph & Phaseolus vulgaris & leaf & Increased GABA levels & O'Leary et al., 2016 \\
\hline Pseudomonas syringae & hemibiotroph & Arabidopsis thaliana & leaf & Increased GABA levels & Park et al., 2010 \\
\hline Ralstonia solanacearum & hemibiotroph & Solanum Iycopersicon & leaf & $\begin{array}{l}\text { Repression of GABA synthesis, } \\
\text { upregulation of GABA catabolism }\end{array}$ & Wang et al., 2019 \\
\hline Botrytis cinerea & necrotroph & Solanum Iycopersicon & leaf & GABA shunt upregulation & Seifi et al., 2013 \\
\hline Cladosporium fulvum & biotroph & Solanum Iycopersicon & leaf & Increased GABA levels & Solomon \& Oliver 2002 \\
\hline Fusarium graminearum & necrotroph & Arabidopsis thaliana & apex & GABA shunt upregulation & Chen et al., 2018 \\
\hline Pyricularia oryzae & hemibiotroph & Oryza sativa & leaf & GABA shunt upregulation & Takahashi et al., 2008 \\
\hline Pyricularia oryzae & hemibiotroph & Oryza sativa & Cell suspension & Increased GABA levels & Forlani et al., 2014 \\
\hline Puccina triticina & biotroph & Triticum aestivum & leaf & Gaba shunt upregulation & Bolton et al., 2008 \\
\hline Rhizoctonia solani & necrotroph & Glyicine max & leaf & Increased GABA levels & Copley et al., 2017 \\
\hline Choristoneura rosaceana & herbivore & Glycine max & leaf & Increased GABA levels & Ramputh \& Shelp ,1996 \\
\hline Spodoptera littoralis & herbivore & Arabidopsis thaliana & leaf & Increased GABA levels & Scholz et al., 2015 \\
\hline
\end{tabular}




\section{viii. Figure legends}

Figure 1. GABA exerts different roles in plant immunity. GABA levels are increased in the plant either by $\mathrm{Ca}^{2+}$ influx involved in PTI and ETI, decreases in the cytosolic $\mathrm{pH}$, or mechanical damage. The accumulated GABA can interfere with quorum sensing (QS) in response to bacterial pathogens, however, some of them are specialized in using GABA as preferred nutrient source (red arrow). Moreover, GABA uptake by herbivores can result in inhibition of GABA neuronal receptors, provoking neuromuscular disorders and abnormal development. Furthermore, GABA boosts endurance as its metabolism sustains host cells against infections by fuelling the TCA cycle and contrasting oxidative damage derived from ROS burst.

Figure 2. Metabolism of GABA and GABA related molecules. The key molecules are classified as those having an indirect or direct role in immune responses (blue and green outlined respectively). Abbreviations are as described in the main text. The biosynthesis of BABA is still uncharacterized in plants, so cannot be directly related to GABA metabolism, however due to their structural similitude, it is expected that it is linked to GABA metabolism at certain level. 


\section{ix. Figures}

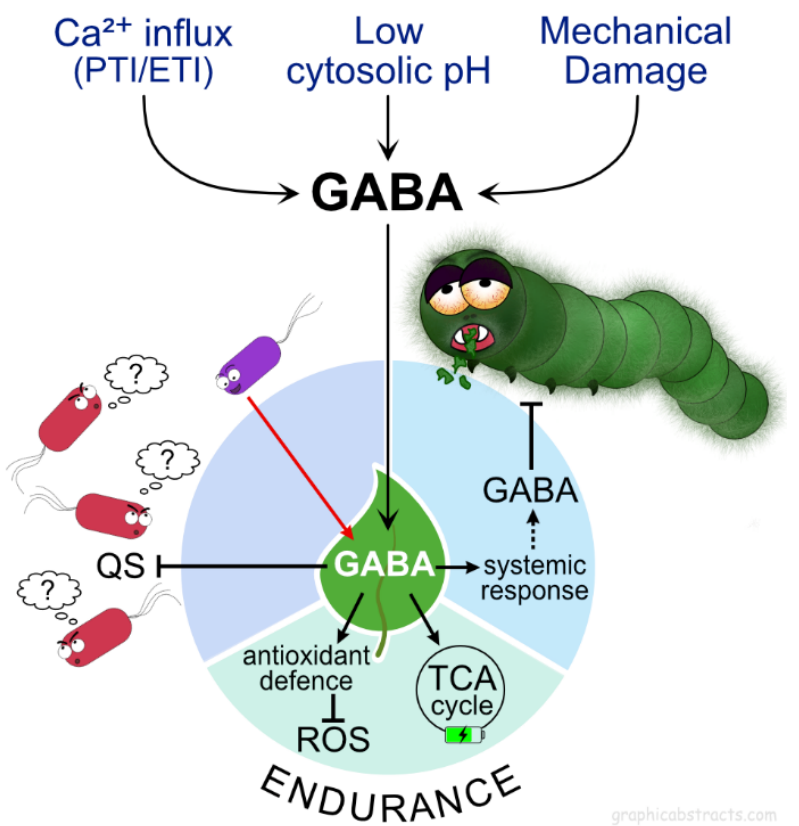

Figure 1. GABA exerts different roles in plant immunity. GABA levels are increased in the plant either by $\mathrm{Ca}^{2+}$ influx involved in PTI and ETI, decreases in the cytosolic $\mathrm{pH}$, or mechanical damage. The accumulated GABA can interfere with quorum sensing (QS) in response to bacterial pathogens, however, some of them are specialized in using GABA as preferred nutrient source (red arrow). Moreover, GABA uptake by herbivores can result in inhibition of GABA neuronal receptors, provoking neuromuscular disorders and abnormal development. Furthermore, GABA boosts endurance as its metabolism sustains host cells against infections by fuelling the TCA cycle and contrasting oxidative damage derived from ROS burst. 


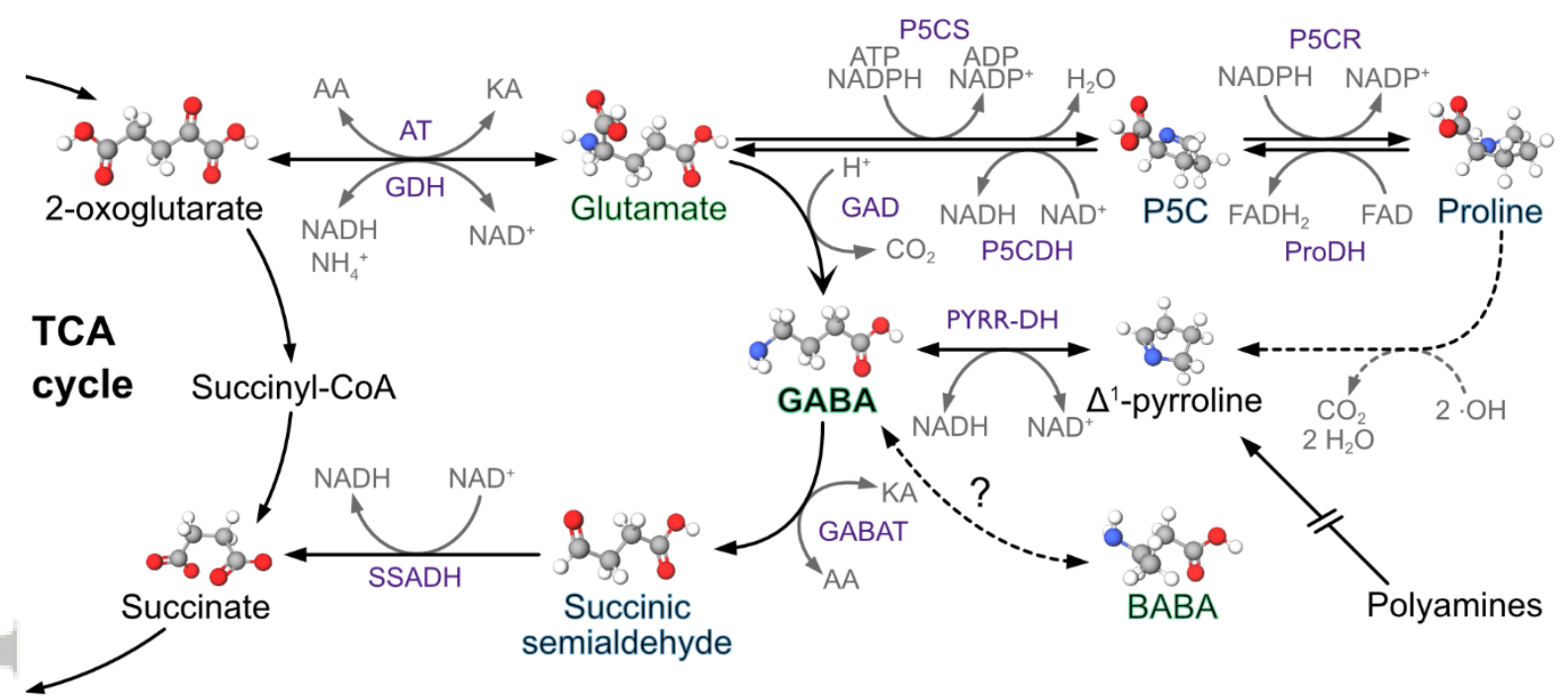

Blue outline: INDIRECT ROLE IN IMMUNE RESPONSES (reducing power, energy supply) Green outline: DIRECT ROLE IN IMMUNE RESPONSES

Figure 2. Metabolism of GABA and GABA related molecules. The key molecules are classified as those having an indirect or direct role in immune responses (blue and green outlined respectively). Abbreviations are as described in the main text. The biosynthesis of BABA is still uncharacterized in plants, so cannot be directly related to GABA metabolism, however due to their structural similitude, it is expected that it is linked to GABA metabolism at certain level. 


\section{Summary statement}

Recent research on GABA in plants highlighted a variety of functions concerning biotic stress responses including its interference with quorum sensing, the enhancement of plant endurance and toxicity to herbivorous. Connections of GABA metabolism with other stress-related amino acids provide further indirect modes of action during the setup of immune responses. 